Check for updates

Cite this: Chem. Commun., 2021, 57, 1006

Received 11th November 2020, Accepted 22nd December 2020

DOI: $10.1039 / \mathrm{d} 0 \mathrm{cc} 07404 \mathrm{~g}$

rsc.li/chemcomm

\section{Rapid access to Asp/Glu sidechain hydrazides as thioester precursors for peptide cyclization and glycosylation $\dagger$}

\author{
Natalie G. Barnes, Kudakwashe Nyandoro, Hanzhang Jin and Derek Macmillan (D)*
}

\begin{abstract}
Head-to-sidechain macrocylic peptides, and neoglycopeptides, were readily prepared by site-specific amidation of aspartic and glutamic acid sidechain hydrazides. Hydrazides, serving as latent thioesters, were introduced through regioselective opening of the corresponding $\mathrm{N}_{\alpha}$-Fmoc protected anhydride precursors.
\end{abstract}

The use of peptide $\mathrm{C}_{\alpha}$-thioesters as building blocks for synthetic proteins using Native Chemical Ligation (NCL) is well established. ${ }^{1}$ These thioesters have additionally functioned as precursors for NCL-mediated head-to-tail peptide cyclisation. ${ }^{2}$ Both C-terminal thioesters and hydrazides (which function as stable thioester precursors) can be readily prepared from synthetic or bacterially produced materials which, in part, overcomes the size limitations associated with traditional stepwise solid phase peptide synthesis (SPPS). ${ }^{3}$ Meanwhile, selective formation of thioesters at the sidechain carboxyl groups of aspartic (Asp) and glutamic (Glu) acids within fully unprotected peptides and proteins is much less common, yet valuable for the production of branched and cyclic peptides possessing novel architectures relevant to natural products, therapeutics, and new biomaterials. For example, bioactive lariat peptides contain a head-to-sidechain macrocycle connecting their $\mathrm{N}$-terminal amino and sidechain carboxyl groups of specific Asp or Glu residues. ${ }^{4}$ Sidechain amidation has also served as a key macrocyclisation strategy for preparation of synthetic stapled peptides, invariably employing fully protected precursors. ${ }^{5}$ Sidechain thioesters are difficult to incorporate into synthetic peptides by Fmoc-based SPPS due to their instability in the presence of piperidine. Consequently, alternative building blocks possessing a latent thioester activated via an $\mathrm{N}-\mathrm{S}(\mathrm{e})$ acyl transfer have been described. ${ }^{6}$ Sidechain acyl hydrazides are also potentially valuable here as air and moisture stable alternatives, but there are only few reports of their use as sidechain thioester

Department of Chemistry, University College London, 20 Gordon Street,

London,WC1HOAJ, UK. E-mail: d.macmillan@ucl.ac.uk

$\dagger$ Electronic supplementary information (ESI) available: Details of all synthetic procedures, and NMR spectra, HPLC traces and LC-MS analysis for selected compounds is available. See DOI: $10.1039 / \mathrm{d} 0 \mathrm{cc} 07404 \mathrm{~g}$ precursors. $^{7}$ Some protected $\mathrm{C}_{\beta / \gamma}$-hydrazide building blocks of $\mathrm{Asp}^{7 a}$ and $\mathrm{Glu}^{8}$ respectively, suitable for use in Fmoc-based SPPS, have previously been prepared albeit by disparate, and often protracted, synthetic pathways.

Here we show how various sidechain protected Asp and Glu hydrazides can be accessed rapidly in only two steps from the corresponding $\mathrm{N}_{\alpha}$-Fmoc protected amino acid, via regioselective opening of the cyclic anhydride. ${ }^{9}$ Protected analogues were introduced to model synthetic peptides to demonstrate their utility in head-to-sidechain macrocyclisation and NCL-like glycosylation (Fig. 1).

Table 1 shows that several protected Asp/Glu building blocks were prepared via regioselective opening of the corresponding Fmoc-protected amino acid anhydride in as little as $1 \mathrm{~h}$.

a)

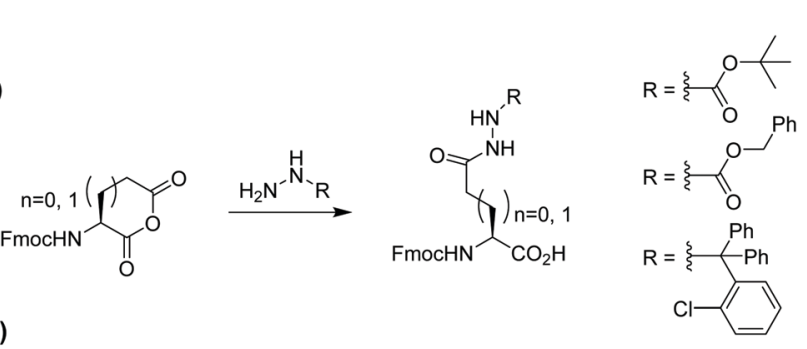

b)

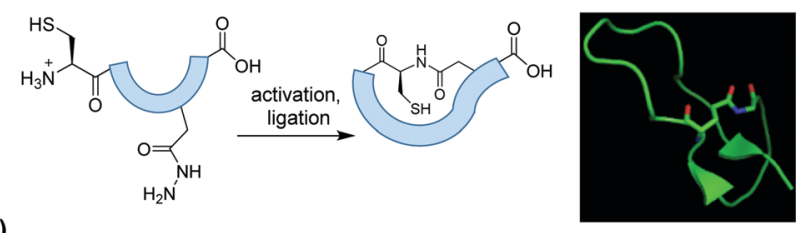

c)

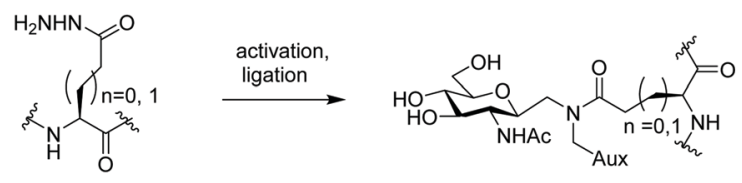

Fig. 1 (a) Rapid synthesis of various sidechain protected Glu and Asp hydrazides by anhydride opening, by reaction with a suitable carbazate or hydrazine (b) Head-to sidechain cyclisation, typical of lariat peptides (inset) and (c) site-selective bioconjugation via NCL. 
Table 1 Synthesis of protected hydrazides from the corresponding anhydrides

\begin{tabular}{|c|c|c|c|c|c|c|}
\hline & 10 & $\mathrm{HN} \prod_{0}$ & & 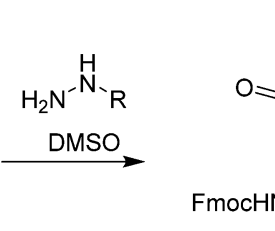 & $\underbrace{\mathrm{H}}_{\mathrm{CO}_{2} \mathrm{H}}$ & \\
\hline Hydrazide & $n$ & $\mathrm{R}^{a}$ & hydra & azine/carbazate equiv. & Time/h & Yield $^{b} / \%$ \\
\hline 1 & 1 & Boc & 1.5 & & 2 & 62 \\
\hline 2 & & $\mathrm{Cbz}$ & 1.5 & & 2 & 88 \\
\hline 3 & & 2-ClTrt & 1.5 & & 16 & 73 \\
\hline 4 & 0 & Boc & 1.5 & & 1 & 77 \\
\hline 5 & 0 & $\mathrm{Cbz}$ & 1.5 & & 1 & 63 \\
\hline 6 & 0 & 2-ClTrt & 1.5 & & 16 & 66 \\
\hline
\end{tabular}

${ }^{a}$ tert-Butyloxycarbonyl (Boc), Benzyloxycarbonyl (Cbz), and 2-Chlorotrityl (2-ClTrt). ${ }^{b}$ Isolated yields following column chromatography, although crude amino acids were often sufficiently pure to be employed directly in peptide synthesis.

Hydrazide building blocks were then introduced to short model peptides derived from microcin J25 (H-GGAGHVPEF-NH ${ }_{2}, 7$ ), ${ }^{10}$ and lassomycin (H-GLRRLFADQ- $\left.\mathrm{NH}_{2}, 8\right) .{ }^{11}$ To assess their performance in NCL-type cyclisation, the N-terminal Gly residues were replaced with Cys, and the target sidechain carboxyl group (indicated in bold) was primed as the hydrazide derivative. 7 was prepared using building block 3 under standard (HBTU/HOBt) coupling, whilst Boc-protected $\mathbf{1}$ failed to couple under similar reaction conditions. Cyclisation at the Glu sidechain via acyl azide $^{3 c}$ and acyl pyrazole ${ }^{12}$ intermediates was then examined (Fig. 2).

In both reactions the desired macrocycle 9 was observed within 1-3 h. In the case of the acyl pyrazole, formed using acetyl acetone (acac) as activator, a mixture of 2-mercaptoethane sulfonic acid (MESNa) thioester and acyl pyrazole were initially observed, both of which were rapidly consumed upon adjusting the $\mathrm{pH}$ to 7. Studies were next extended to Asp derivatives and model peptide 8. Unfortunately all Asp derivatives 4-6 failed to couple efficiently under identical reaction conditions employed to prepare 7. These results underscored the utility of the $\mathrm{C}_{\beta}$-benzyl ester of Asp as a useful alternative hydrazide precursor. $^{7 b}$ Coincidentally, the benzyl ester could also be prepared by regioselective opening of the Fmoc protected aspartic anhydride with benzyl alcohol (see ESI $\dagger$ ).

Encouragingly coupling of $\mathbf{4}$ or $\mathbf{6}$ via the symmetrical anhydride method $^{13}$ allowed 8 to be isolated in 14\% yield from a crude mixture comprising significant deletion by-product (H-CLRRLFAQ- $\mathrm{NH}_{2}$ ). Cyclisation was attempted following $\mathrm{NaNO}_{2}$ activation (Fig. 3). Mindful that aspartimide formation could potentially compete with NCL upon hydrazide activation, giving rise to a product of identical mass, the isolated product was treated with trypsin $\left(0.01 \mathrm{mg} \mathrm{ml}^{-1}\right.$ trypsin, $\mathrm{pH} 8,30^{\circ} \mathrm{C}, 1.5 \mathrm{~h}$ ). Successful formation of $\mathbf{1 0}$ was confirmed by the appearance of two major species (see ESI $\dagger$ ) with $\mathrm{m} / \mathrm{z}=1120.6$, corresponding to amide bond hydrolysis at one of the scissile arginine (Arg) residues, and $m / z=964.5$, corresponding to excision of one Arg residue. Had cyclisation been unsuccessful we would have expected to observe cleavage products resulting from loss of all a)
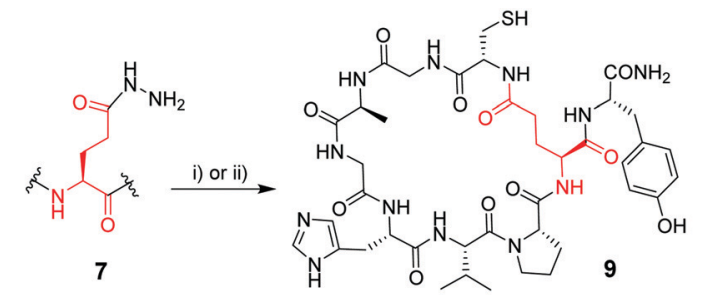

bi)

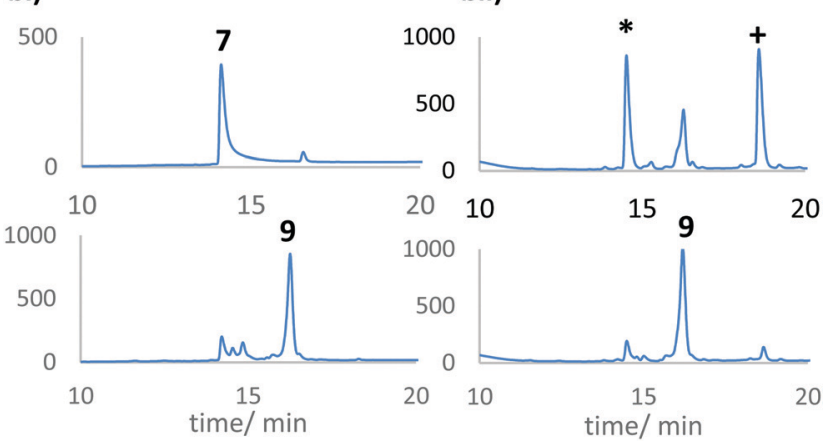

Fig. 2 (a) Acyl hydrazide activation to form macrocycle $\mathbf{9}$, monitored by HPLC. (bi) Upper trace shows initial hydrazide 7 while the lower trace shows the reaction mixture after $\mathrm{NaNO}_{2}$ activation $\left(20 \mathrm{~min}\right.$ at $\mathrm{pH} 3,0{ }^{\circ} \mathrm{C}$ ), followed by addition of sodium 2-mercaptoethane sulfonate (MESNa), $1 \mathrm{~h}$, $\mathrm{RT}, \mathrm{pH} \mathrm{7.}{ }^{3 \mathrm{c}}$ (bii) Activation of 7 with acetyl acetone (acac)/MESNa ( $\mathrm{pH} 3-4$, $2 \mathrm{~h}$, upper trace) leads to a mix of MESNa thioester $\left({ }^{*}\right)$ and acyl pyrazole $(+)$ which are both consumed upon adjusting to $\mathrm{pH} 7$ for $1 \mathrm{~h}$ (lower trace). ${ }^{12}$

a)

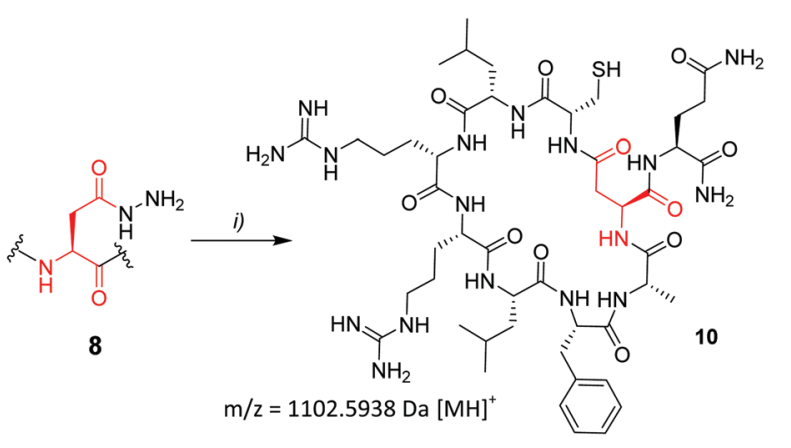

b)

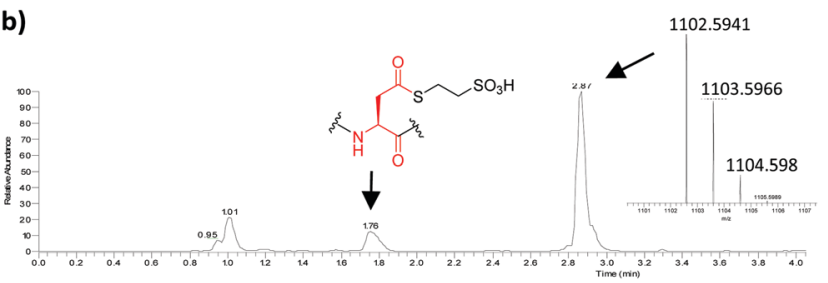

Fig. 3 (a) Cyclisation of Lassomycin derivative 8. (i) $\mathrm{NaNO}_{2}$ (1.2 equiv. $\mathrm{Na}$ phosphate buffer; $\left.\mathrm{pH} 3,0{ }^{\circ} \mathrm{C}, 20 \mathrm{~min}\right)$, followed by addition of MESNa $(\mathrm{pH} 7$, rt, $48 \mathrm{~h}$ ). (b) LC-MS trace of the reaction mixture after $24 \mathrm{~h}$, showing 10 as the major species.

$4 \mathrm{~N}$-terminal residues. Overall the cyclisation product was isolated in $64 \%$ yield.

Sidechain hydrazide activation and NCL is not limited to intramolecular reactions. In initial attempts to extend this process to include convergent $\mathrm{N}$-glycopeptide synthesis, we explored the reaction between sugar-linked auxiliary $\mathbf{1 1}^{\mathbf{1 4 , 1 5}}$ 

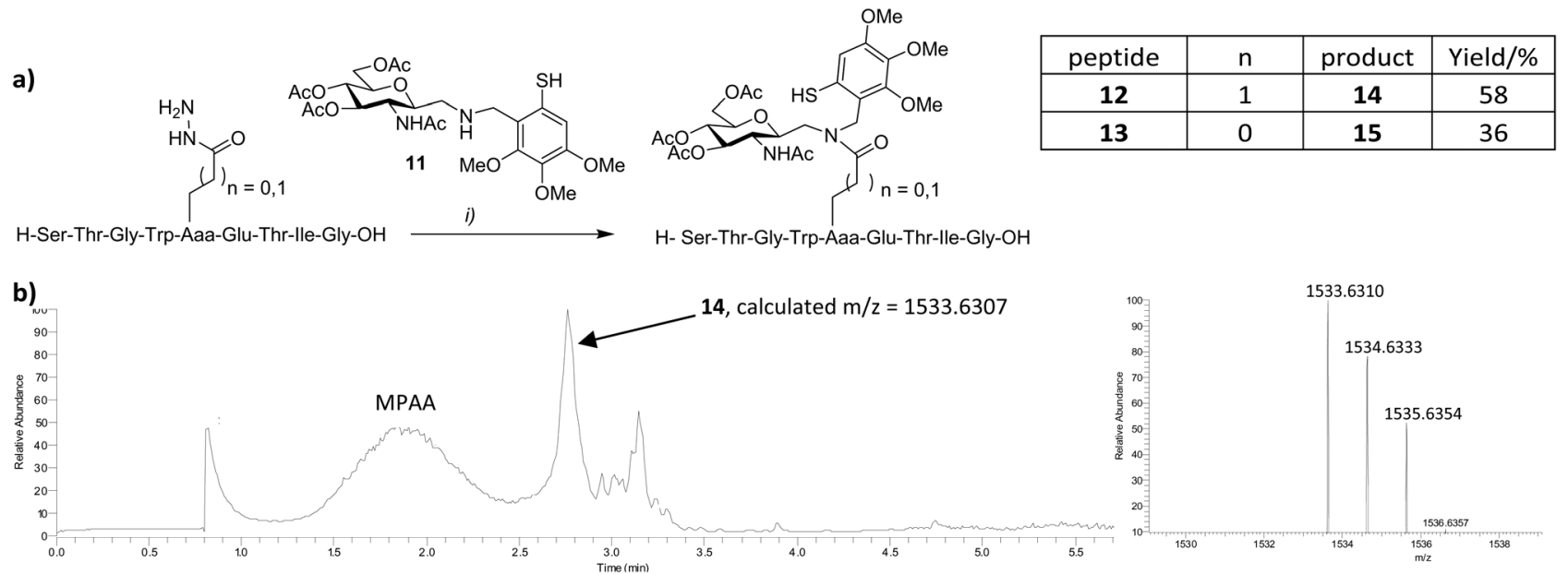

Fig. 4 (a) Convergent $\mathrm{N}$-neoglycopeptide synthesis: (i) acac (2 equiv.), $0.1 \mathrm{M} \mathrm{MPAA}$, Na phosphate buffer pH 3, $2 \mathrm{~h}$, then, 11 and TCEP (50 mM), pH 7, $48 \mathrm{~h}$. (b) LC-MS analysis of the reaction mixture after $48 \mathrm{~h}$ showing predominance of glycoconjugate 14 .

and peptides 12-13 (Fig. 4). Auxiliary-mediated ligation removes the requirement for cysteine to be incorporated at the ligation site. ${ }^{16}$ Peptides 12 and 13 , corresponding to a glycosylated fragment of $\beta$-interferon, were prepared as their Glu and Asp sidechain hydrazides respectively, in a similar manner to 7 and 8. Alternatively $\mathbf{1 3}$ was prepared from the Asp sidechain benzyl ester (see ESI $\dagger$ ). Whilst conversion from the benzyl ester to the hydrazide proceeded well ( $96 \%$ yield), in our hands much of the benzyl ester precursor itself (isolated in 19\% yield) was lost due to competing aspartimide formation that occurred during peptide synthesis, cleavage and isolation. Consequently, syntheses employing the hydrazides $\mathbf{4}$ or $\mathbf{6}$, appeared comparable in terms of efficiency. $\mathbf{1 1}$ was employed in ligation reactions as a chemically robust alternative to the naturally occurring glycosylamine derived from $N$-acetyl glucosamine. ${ }^{16}$ The additional methylene spacer at the anomeric centre additionally serves to render eventual glycopeptide products resistant to enzymatic protein deglycosylation mediated by N-glycanases. ${ }^{17}$ Peptides 12 or $\mathbf{1 3}$ were treated with acac in sodium phosphate buffer at $\mathrm{pH}$ 3-4 for $2 \mathrm{~h}$, followed by addition of 11, 4-mercaptophenyl acetic acid (MPAA) and tris-carboxyethylphosphine (TCEP) at pH 7, and monitored by LCMS. Ligation products were observed after $1 \mathrm{~h}$ and continued to accumulate over time, emerging as the major products after $48 \mathrm{~h}$ (Fig. 4b). Glycoconjugates $\mathbf{1 4}$ and $\mathbf{1 5}$ were isolated by preparative HPLC in 58 and $36 \%$ yields respectively.

In summary, we have shown that Asp and Glu hydrazide derivatives, compatible with Fmoc-based SPPS, can be simply and rapidly prepared from their amino acid anhydrides. As stable thioester precursors, they facilitate cyclisation at the amino acid sidechain upon activation with acac or $\mathrm{NaNO}_{2}$. Both activation methods are known for their broad amino acid tolerance and are applied widely in NCL processes. ${ }^{3 f, 12}$ Furthermore, we showed that glycopeptide analogues could be prepared using an auxiliary mediated NCL-type approach. Glycoaminoacid building blocks for use in Fmoc-based SPPS have previously been prepared using regioselective opening of Asp anhydrides. ${ }^{9 a}$ However these building blocks still require introduction into synthetic peptide thioester segments, to enable protein backbone assembly via NCL. With recombinant protein sidechain thioesters already available through an expanded genetic code ${ }^{18}$ the convergent union of carbohydrates with fully recombinant proteins is edging closer. ${ }^{19}$ It is likely that genetically encoded hydrazide building blocks will also become available in the future, functioning as versatile intermediates on the path to modified proteins. We envisage that fully recombinant proteins modified with $\mathbf{1 1}$, or auxiliarylinked $N$-acetyl glucosamine, may provide a viable convergent route to glycoprotein therapeutics. Once installed, the monosaccharide can be extended enzymatically using endo-glucosidases, ${ }^{20}$ dramatically reducing the requirement for protein synthesis by multi-component NCL.

The authors acknowledge financial support from The Leverhulme Trust (RPG-2018-133) and UCL.

\section{Conflicts of interest}

There are no conflicts to declare.

\section{References}

1 (a) V. Agouridas, O. El Mahdi, V. Diemer, M. Cargoët, J.-C. M. Monbaliu and O. Melnyk, Chem. Rev., 2019, 119(12), 7328-7443; (b) A. C. Conibear, E. E. Watson, R. J. Payne and C. F. W. Becker, Chem. Soc. Rev., 2018, 47, 9046-9068; (c) L. R. Malins and R. J. Payne, Curr. Opin. Chem. Biol., 2014, 22, 70-78; (d) S. B. H. Kent, Chem. Soc. Rev., 2009, 38, 338-351.

2 J. P. Tam and C. T. T. Wong, J. Biol. Chem., 2012, 287, $27020-27025$.

3 (a) N. H. Shah and T. W. Muir, Chem. Sci., 2014, 5, 446-461; (b) A. L. Adams, B. Cowper, R. E. Morgan, B. Premdjee, S. Caddick and D. Macmillan, Angew. Chem., Int. Ed., 2013, 52, 13062-13066; (c) J.-S. Zheng, S. Tang, Y. Guo, H.-N. Chang and L. Liu, ChemBioChem, 2012, 13, 542-546; (d) Y.-M. Li, M.-Y. Yang, Y.-C. Huang, Y.-T. Li, P. R. Chen and L. Liu, ACS Chem. Biol., 2012, 7, 1015-1022; (e) G.-M. Fang, Y.-M. Li, F. Shen, Y.-C. Huang, J.-B. Li, Y. Lin, H.-K. Cui and L. Liu, Angew. Chem., Int. Ed., 2011, 50, 7645-7649; $(f)$ Y.-C. Huang, G.-M. Fang and L. Liu, Nat. Sci. Rev., 2015, 3, 107-116. 


\section{Communication}

4 (a) H. Martin-Gómez and J. Tulla-Puche, Org. Biomol. Chem., 2018, 16, 5065-5080; (b) J. D. Hegemann, M. Zimmermann, X. Xie and M. A. Marahiel, Acc. Chem. Res., 2015, 48, 1909-1919.

5 Y. H. Lau, P. de Andrade, Y. Wu and D. R. Spring, Chem. Soc. Rev., 2015, 44, 91-102.

6 (a) L. Raibaut, H. Drobecq and O. Melnyk, Org. Lett., 2015, 17, 3636-3639; (b) D. J. Castillo-Pazos and D. Macmillan, Synlett, 2017, 1923-1928; (c) E. Boll, J. Dheur, H. Drobecq and O. Melnyk, Org. Lett., 2012, 14, 2222-2225.

7 (a) J. Lu, X.-B. Tian and W. Huang, Chin. Chem. Lett., 2015, 26, 946-950; (b) X. Tian, P. Yu, Y. Tang, Z. Le and W. Huang, Synlett, 2017, 1966-1970.

8 (a) K. Hofmann, A. Lindenmann, M. Z. Magee and N. H. Khan, J. Am. Chem. Soc., 1952, 74, 470-476; (b) D. Gazis, J. Glass, I. L. Schwartz, G. Stavropoulos and D. Theodoropoulos, Int. J. Pept. Protein Res., 1989, 34, 353-357; (c) C. M. Haney and W. S. Horne, J. Pept. Sci., 2014, 20, 108-114.

9 (a) F. M. Ibatullin and S. I. Selivanov, Tetrahedron Lett., 2009, 50, 6351-6354; (b) X. Huang, X. Luo, Y. Roupioz and J. W. Keillor, J. Org. Chem., 1997, 62, 8821-8825.

10 M. J. Bayro, J. Mukhopadhyay, G. V. T. Swapna, J. Y. Huang, L.-C. Ma, E. Sineva, P. E. Dawson, G. T. Montelione and R. H. Ebright, J. Am. Chem. Soc., 2003, 125, 12382-12383.

11 S. Lear, T. Munshi, A. S. Hudson, C. Hatton, J. Clardy, J. A. Mosely, T. J. Bull, C. S. Sit and S. L. Cobb, Org. Biomol. Chem., 2016, 14, $4534-4541$.
12 D. T. Flood, J. C. J. Hintzen, M. J. Bird, P. A. Cistrone, J. S. Chen and P. E. Dawson, Angew. Chem., Int. Ed., 2018, 57, 11634-11639.

13 (a) J. Meienhofer, M. Waki, E. P. Heimre, T. J. Lambros, R. C. Makofske and C.-D. Chang, Int. J. Pept. Protein Res., 1979, 13, 35-42; (b) M. Goodman, C. Toniolo, L. Moroder and A. L. Felix, Houben-Weyl Methods in Organic Chemistry, Volume E22, - Synthesis of Peptides and Peptidomimetics, Thieme Medical Publishers Inc, 2004, pp. 495-516.

14 D. Carrière, S. J. Meunier, F. D. Tropper, S. Cao and R. Roy, J. Mol. Catal. A: Chem., 2000, 154, 9-22.

15 F. Burlina, A.-B. M. Abdel-Aal, R. Raz, I. Pinzuti, G. Papageorgiou, J. Li, R. Antrobus, S. R. Martin, S. Kunzelmann, B. Stieglitz and J. Offer, Commun. Chem., 2019, 2, 111.

16 H. Chai, K. Le Mai Hoang, M. D. Vu, K. Pasunooti, C.-F. Liu and X.-W. Liu, Angew. Chem., Int. Ed., 2016, 55, 10363-10367.

17 L.-X. Wang, M. Tang, T. Suzuki, K. Kitajima, Y. Inoue, S. Inoue, J.-Q. Fan and Y. C. Lee, J. Am. Chem. Soc., 1997, 119, 11137-11146.

18 W. Xuan, D. Collins, M. Koh, S. Shao, A. Yao, H. Xiao, P. Garner and P. G. Schultz, ACS Chem. Biol., 2018, 13, 578-581.

19 N. Holloran, D. Collins, U. Rathnayake, B. Zhang, M. Koh, C. Kang and P. Garner, Bioconjugate Chem., 2020, 31, $2362-2366$.

20 A. J. Fairbanks and Curr Opin., Chem. Biol., 2019, 53, 9-15. 